\title{
Andrzej Klimczuk (2015). Economic Foundations for Creative Ageing Policy. Context and Considerations. Volume 1. New York: Palgrave Macmillan, 232 pp. ISBN 9781137465337 (hardcover)
}

\author{
REVIEWED BY Michael FINE*
}

Klimczuk's book, Economic Foundations for Creative Ageing Policy, is remarkable not only for the vast literary scholarship it has entailed or for the ambitious approach he has brought to his topic, but also for the creative licence he has taken with the use of the term "creative ageing." In his hands, creative ageing has transformed from a phrase used to describe the pursuit of creative activities and crafts by those who are ageing to become a vision for ageing societies.

The term "creative ageing," encountered ever more frequently in recent years, was first proposed in 1960s by Edward LeRoy Borz (Bortz 2012; orig 1963), and was later popularised by others, the U.S. psychiatrist Gene Cohen in particular, who in 1995 famously described it as "like chocolate for the brain." In this formulation, creative ageing concerns the pursuit of creative activities and crafts by older people. It can work as a therapy for those requiring ongoing care, a life interest, occupation, identity or as a new hobby for those liberated from employment after retirement. The full range of creative activities is perhaps not possible to elaborate, 
International Journal of Ageing and Later Life

but extends from singing and music making of various kinds to reading and writing, painting, sculpture, dance, acting and dramaturgical performance, and into the cyber world of computing and beyond. As Vera Gallistl and others have recently noted, creativity in later life is no longer exclusive to older artists but has instead come to be promoted as an enhancement of mind, body and social relations for a majority of the older population (Gallistl 2018).

Klimczuk's book takes the concept well beyond this apparently limited meaning to become a vision for something even grander in scope and scale - a social transformation in which population ageing is no longer seen as a problem or social burden to be managed. Instead of being confined to artistic endeavours, creativity, following the path of sociologist Richard Florida and many others, is seen as the transformative characteristic of successful post-modern economies, regions, corporations and social classes. Therefore, "creative ageing" has become a metaphorical way of leveraging social change, drawing on and extending the capabilities not just of older people but of all ages, serving as both an intergenerational means and end, a new blueprint for policy and social life in the $21^{\text {st }}$ century and beyond.

Continuing his trickster approach to this topic, the focus on the "economic foundations" for policy turns out to have little to do with what is usually understood as economics. Instead of addressing topics such as demand and supply, production, consumption, prices, marketing, national budgets, economic growth or fiscal crisis as conventional economists might, the economics involved in this publication turns out be a much more abstract discussion of different perspectives on society and forms of economic activity.

In this way, having discussed old age as a stage of life in the opening chapter, Klimczuk goes on to review the literature on different forms of "older people's capital" in Chapter 2. The chapter does not discuss about costs of an ageing population, but about the meanings of terms such as human and social capital, cultural capital and creative capital. Chapter 3 reviews literature on creativity and ageing, before chapter 4 considers the concept of the mixed economy of welfare. Chapter 5 is the key chapter; it focusses on three different forms of economy - the 
silver, creative and social economies - which he asserts are the economic foundations for ageing. In Chapter 6, he discusses writings that consider the interaction between these economic systems before finishing with a brief concluding chapter that advocates breaking down barriers to such a creative ageing policy.

This is a book that both excites and frustrates. The author's approach is essentially to present a vast literature review - or perhaps better said, to summarise the results of the literature search, mostly published in English and also to make a considerable volume of Polish language research accessible to English speakers. In this way, each chapter is a treasure trove of useful summaries of a vast number of key books and articles on the topics of his choosing. These lay a trail, like breadcrumbs, towards his final chapters, their pathway and destination revealed as the work proceeds rather than following a theory or argument laid out clearly from the beginning.

Little is done to critique the research cited or to explore its theoretical assumptions or limitations and this work reads in parts like a PhD thesis based on secondary sources. The approach has the advantage of allowing him to bring together research from a wide range of disciplines, creating something like a dialogue between authors who might normally be seen to come from opposite ends of political or philosophical traditions. Although the accumulation of ideas builds up to gradually take the shape of a proposition, Klimczuk has fallen short by not elaborating more clearly the conceptual approach of this scheme. Yet it would be wrong to dismiss the approach or the conclusions. This remarkable, if at times, frustrating tome deserves to be widely read, not only by gerontologists but also by social researchers concerned with charting a course for progressive social change into the future.

\section{References}

Bortz, E. L. R. (2012; orig 1963). Creative Aging. Literary Licensing, LLC. Original edition: Macmillan, The University of Michigan.

Gallistl, V. (2018). The emergence of the creative ager - On subject cultures of late-life creativity. Journal of Aging Studies 46: 93-99. 